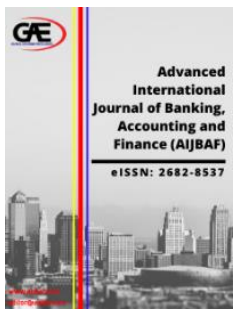

\author{
ADVANCED INTERNATIONAL JOURNAL OF \\ BANKING, ACCOUNTING AND FINANCE \\ (AIJBAF) \\ www.aijbaf.com
}

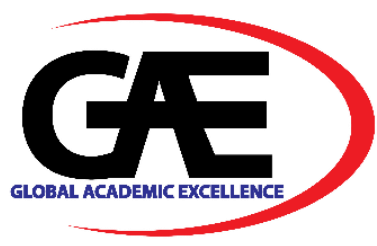

\title{
BAYESIAN MIXTURE LAPLACE AUTOREGRESSIVE MODELING TO ESTIMATE VALUE-AT-RISK IN E-COMMERCE STOCKS
}

\author{
Brina Miftahurrohmah $^{1 *}$, Yogantara Setya Dharmawan ${ }^{2}$, Catur Wulandari $^{3}$ \\ 1 Department of Information System, Universitas Internasional Semen Indonesia, Indonesia \\ Email: brina.miftahurrohmah@uisi.ac.id \\ 2 Department of Information System, Universitas Internasional Semen Indonesia, Indonesia \\ Email: yogantara.dharmawan@uisi.ac.id \\ 3 Department of Information System, Universitas Internasional Semen Indonesia, Indonesia \\ Email: catur.wulandari@uisi.ac.id \\ * Corresponding Author
}

\section{Article Info:}

\section{Article history:}

Received date:08.11.2020

Revised date: 15.11 .2020

Accepted date: 17.11 .2020

Published date: 01.12.2020

\section{To cite this document:}

Miftahurrohmah, B., Dharmawan, Y. S., \& Wulandri, C. (2020). Bayesian Mixture Laplace Autoregressive Modeling to Estimate Value-at-Risk in E-Commerce Stocks. Advanced International Journal of Banking, Accounting, and Finance, 2 (5), 21-33.

DOI: $10.35631 /$ AIJBAF.25002.

This work is licensed under CC BY 4.0

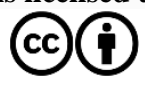

Abstract:

The e-commerce business is growing in Indonesia. However, there are not many e-commerce companies that trade their shares on the Exchange. Since the emergence of startups in Indonesia, including the emergence of four technology companies with unicorn status, only three have registered. These companies, namely PT. M-Cash Integration Tbk (MCAS), PT. Kioson Commercial Indonesia Tbk (KIOS) and PT. NFC Indonesia Tbk (NFCX), are listed on the development board. To enliven the stock market of e-commerce companies, it is necessary to analyze the risk value of daily closing price data as an investment consideration. This study aims to provide knowledge to investors who want to invest in e-commerce companies about possible risks. This research was conducted on two e-commerce companies that were first listed on the IDX, namely MCAS and KIOS. The Value-at-Risk (VaR) method with the Bayesian Mixture Laplace Autoregressive (MLAR) approach is used to determine the risk value of the company's shares. Accurate VaR based on backtesting on each company's shares has been obtained at 5\%-quantile, 0.0384 for MCAS, and 0.0622 for KIOS in 1-day horizon investment.

Keywords:

E-commerce, Stock, Value-at-Risk, Bayesian, MLAR 


\section{Introduction}

The development of e-commerce in Indonesia is currently very fast. According to the Lembaga Strategi Ketahanan Ekonomi (LSKE) Kadin Indonesia, this is because many Indonesians use the internet and smartphones. This statement is reinforced by data from the Ministry of Communication and Informatics which states that currently there are 93.4 million internet users and 71 million smartphone users, and this figure is predicted to continue to grow. (Laucereno, 2019). However, data from the Indonesia Stock Exchange (IDX) shows that only three ecommerce companies have registered their shares on the IDX, namely PT NFC Indonesia Tbk (NFCX), PT M Cash Integration Tbk (MCAS), and PT Kioson Commercial Indonesia Tbk (KIOS). Head of Research for Indonesian Capital Connections Alfred Nainggolan stated that the reason e-commerce companies are still reluctant to enter the stock exchange is that the market has difficulty accepting and equating their perceptions with other sectors, in this case, the non-e-commerce sector. Besides, Alfred also stated that the unstable regulations were the trigger for this (Sidik, 2019).

The Minister of Communication and Informatics of the Republic of Indonesia Rudiantara encourages and hopes that other e-commerce with unicorns will register shares on the IDX following the three previously registered companies. It is felt that this will be difficult to realize if you look at the conditions previously described because these conditions represent a significant risk for the market in the e-commerce sector. Issuers have to think hard to convince the market that the e-commerce sector will one day be strong. In this regard, the researcher wants to provide an overview of the risks that will be faced by investors in making decisions about investing in stocks of e-commerce companies listed on the Indonesia Stock Exchange (IDX) optimally based on the risk value.

This study proposes the use of the VaR method with Bayesian Mixture Laplace Autoregressive (MLAR) which will be implemented to analyze the risks of two e-commerce companies that were first listed on the IDX, namely MCAS and KIOS. Bayesian MLAR was developed by Miftahurrohmah, Iriawan, and Fithriasari (2017) from previous research by Nguyen, Geoffrey, Ullmann, \& Janke (2016) which states that by using the Laplace distribution the results obtained will be more robust than using the Normal distribution. Also, the results of the comparison of the Bayesian MLAR method with the Normal Autoregressive Mixture (MNAR) that have been carried out by Putri (2016) concluded that the analysis using the Bayesian MLAR approach produces a better predictive model than the Bayesian MNAR approach. The return distribution of the three-pointed stocks resembles the Laplace distribution and it is indicated that there is a multimodal also the reason for using this method. Thus, it is hoped that in this study the best Bayesian MLAR model will be obtained for the three stocks so that an accurate VaR will be obtained. Accurate VaR calculations are very important to do to provide knowledge to investors who want to invest in e-commerce companies, by looking at daily stock prices and the value of the risks to be faced. 


\section{Literature Review}

\section{Laplace Distribution}

The classic Laplace distribution is a probability distribution with a probability distribution function (pdf)

$$
f(y ; \mu, \sigma)=\frac{1}{2 \sigma} e^{-|y-\mu| / \sigma},-\infty<y<\infty,
$$

where $\mu \in(-\infty, \infty)$ and $\sigma>0$ are location and scale parameters. In this case, the standard Laplace distribution is determined by $\mu=0$ and $\sigma=1$. Cumulative Distribution Function $(\mathrm{CDF})$ of this distribution

$$
F(y ; \mu, \sigma)= \begin{cases}\frac{1}{2} e^{-|y-\mu| / \sigma} & ; y \leq \mu \\ 1-\frac{1}{2} e^{-|y-\mu| / \sigma} & ; y \geq \mu\end{cases}
$$

The differences between the classical and standard Laplace distributions are visualized in Figure 1.

The consequence is that the mean, median, and mode of this distribution are all equal to $\mu$ (Kotz, Kozubowski, \& Podgorski, 2001).

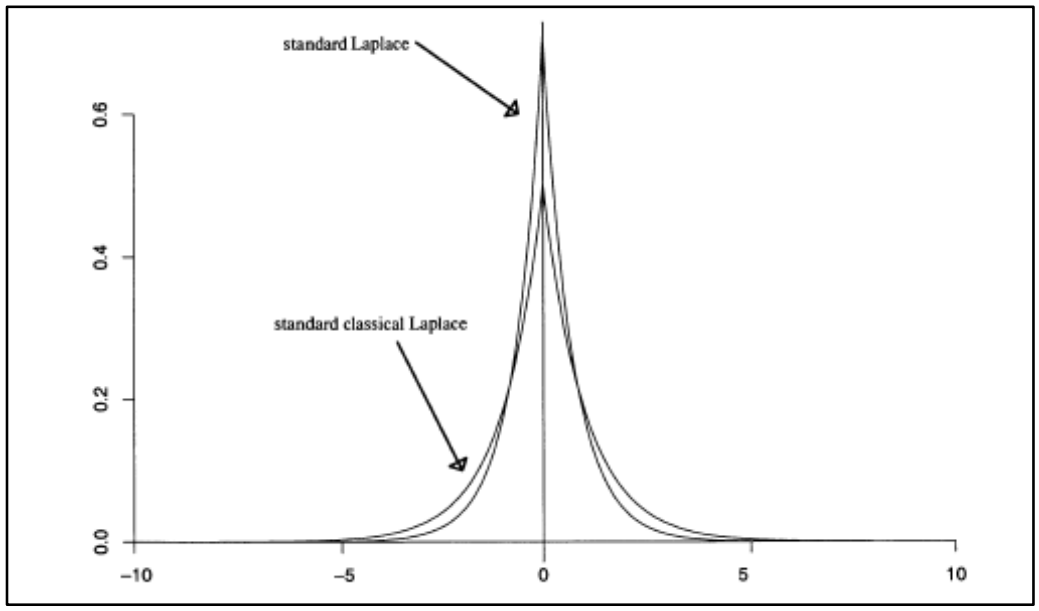

Figure 1: Laplace Distribution Plots

\section{Mixture Laplace Autoregressive (MLAR)}

The Mixture Laplace Autoregressive is developed from the AR model (Autoregressive model) which consists of a combination of $\mathrm{K}$ components of the Laplace conditional, as an alternative to the MAR model. The Laplace Autoregressive (MLAR) mixture is a model introduced by Nguyen, et al. (2016) using the combined Laplace conditional model, as an alternative to the MAR model (Nguyen, Geoffrey, Ullmann, \& Janke, 2016). Like the AR model, the MLAR Model also requires stationary conditions. Nguyen and McLachan (2016) also said that the 
Normal assumption applied to the residuals is sensitive to outliers. With MLAR, the problems that occur when the Normal assumption for residuals is not met will be resolved. $Y_{t}$ is formed from a $\mathrm{K}$ component of the MLAR order $\mathrm{p}$ model $\left(\operatorname{MLAR}(K, p)\right.$ model), if $Y_{t} \mid \mathfrak{\Im}_{t-1} ; \boldsymbol{\vartheta}$ has a density

$$
F\left(y_{t} \mid \mathfrak{\mho}_{t-1} ; \boldsymbol{\vartheta}\right)=\sum_{j=1}^{K} \pi_{j} \lambda\left(y_{t} ; \phi_{j, i 0}+\sum_{i=1}^{p} \boldsymbol{\phi}_{j i, i} y_{t-i}, \sigma_{j}\right)
$$

where

$$
\lambda(y ; \mu, \sigma)=(\sigma \sqrt{2})^{-1} \exp (-\sqrt{2}|x-\mu| / \sigma)
$$

is Laplace density function with mean $\mu$, variance $\sigma^{2}$ and

$$
\boldsymbol{\vartheta}=\left(\pi_{1}, \pi_{2}, \ldots, \pi_{K}, \boldsymbol{\phi}_{1}^{T}, \boldsymbol{\phi}_{2}^{T}, \ldots, \boldsymbol{\phi}_{K}^{T}, \sigma_{1}, \sigma_{2}, \ldots, \sigma_{K}\right)^{T}
$$

is the parameter vector of mixed models. The residual of the MLAR model is also considered to have a Laplace distribution (Nguyen \& McLachlan, Laplace mixture of linear experts, 2016).

\section{Estimating and Testing Parameter}

The Bayesian model is developed from the Bayes method which is based on the Bayes theorem. Its posterior distribution can be defined

$$
p(\boldsymbol{\theta} \mid y) \propto f(y \mid \boldsymbol{\theta}) p(\boldsymbol{\theta})
$$

This model is built by combining the prior distribution which represents information about the unsure parameter with the probability distribution from the new data to produce a posterior distribution. The posterior distribution obtained is then used for drawing conclusions and making decisions.

The algorithm commonly used to estimate parameter $\boldsymbol{\theta}$ in Bayesian analysis is the Markov Chain Monte Carlo (MCMC) algorithm. This parameter is then corrected to obtain a value of $\boldsymbol{\theta}$ that is closer to the target of the posterior distribution of $p(\boldsymbol{\theta} \mid y)$. The way this method works is by sampling the $\theta$ value in a sequence. The sample taken depends on the last sample taken previously by determining the initialization $\theta$ at the start of the sampling, thus the sample is taken forms the Markov Chain $\theta^{1}, \theta^{2}, \ldots, \theta^{b}$ chain. The distribution of the given $\theta^{b}$ depends only on all the preceding $\boldsymbol{\theta}$ at the most recent value which is $\theta^{b-1}$. This process is carried out until the conditions converge which is indicated by the shape of the stationary chain.

Gibbs Sampling algorithm is one of the MCMC algorithms that can solve multidimensional problems. In Normal case $\boldsymbol{\theta}=(\mu, \sigma, w)$ and posterior is $p(\mu, \sigma, w \mid y)$. The Gibbs sampler will help estimate $\mu, \sigma$, and $w$ iteratively following the sampling scheme.

1. Given state: $\boldsymbol{\theta}^{b}=(\mu, \sigma, w)^{b}$ in iteration $b=0$.

2. Generating component parameters of each mixture.

$$
\text { a. } \mu^{(b+1)} \text { generate from } p\left(\mu \mid y, \sigma^{(b)}, w^{(b)}\right) \text {. }
$$


b. $\sigma^{(b+1)}$ generate from $p\left(\sigma \mid y, \mu^{(b+1)}, w^{(b)}\right)$.

c. $w^{(b+1)}$ generate from $p\left(w \mid y, \mu^{(b)}, \sigma^{(b+1)}\right)$.

3. Repeat step two $T$ times, $T \rightarrow \infty$.

In estimating the MLAR parameter, step 2 must estimate as much as $\mathrm{K}$ of the mixture components of both $\mu, \sigma$, and $w$. The data generated by using the algorithm above will have a convergent and stationary data pattern and will be proportional to their respective distributions.

The parameter significance test is used to determine which parameters are significant so that they can be used in the model. Testing the parameter of the estimation result with Bayesian MCMC for each parameter obtained is done with the null hypothesis is $\theta=0$ and the alternative hypothesis is $\theta \neq 0$. The null hypothesis is rejected if in confidence interval $(1-\alpha)$ of posterior, credible interval did not contain null.

\section{Value at Risk (VaR)}

Value at Risk (VaR) or also known as Quantile Risk Metrics describes the estimate of the maximum loss that may occur in a bank portfolio due to market risk within a certain time and a certain level of statistical confidence. According to Butler (1999), VaR is the dominant methodology for estimating exactly how much money is at risk every day in financial markets. Based on the definition of VaR, talking about VaR cannot be separated from the term risk. Risk is a combination of the chances of an event with its consequences or consequences.

From various definitions, the risk is associated with the possibility of an unwanted or unexpected bad result (loss). In other words, the possibility already indicates uncertainty. Therefore, to avoid unwanted risks, VaR is calculated. Miftahurrohmah, Iriawan, and Kartika (2017) have developed a VaR calculation based on the Laplace distribution, making it suitable for the case of Bayesian MLAR modeling. The mathematical equation for calculating VaR on the $h$ - time horizon is

$$
\mathrm{VaR}_{\text {mix }}=\pi_{1} \sqrt{h} \mathrm{VaR}_{1, \alpha}+\pi_{3} \sqrt{h} \mathrm{VaR}_{1, \alpha}+\cdots+\pi_{K} \sqrt{h} \mathrm{VaR}_{1, \alpha}
$$

\section{Backtesting}

Backtesting is a statistical procedure in which the actual gains and losses are systematically compared with the estimated VaR. The most widely used backtesting test is the Kupiec test. Kupiec Test developed by is Kupiec (1995) a backtesting procedure used for some VaR modeling studies (Abad, Benito, \& López, 2013) (Iorgulescu, 2012) (Summinga-Sonagadu \& Narsoo, 2019). The Kupiec test, also known as the POF (Proportion Of Failure) test, measures whether the number of exceptions is consistent with the $\alpha^{\text {th }}$ quantile (Dowd, 2006). The number of exceptions following binomial distribution. Because that, the information needed to perform the Kupiec test is the number of observations $(T)$, the number of exceptions $(x)$, and the $\alpha^{\text {th }}$ quantile (Kansantaloustiede, Tutkielma, \& Nieppola, 2009). The null hypothesis of this test is $p=\hat{p}$ and the alternative hypothesis is $p \neq \hat{p}$. The test statistic used is the likelihood ratio $(L R)$ (Kupiec, 1995). 


$$
L R=-2 \ln \left(\frac{(1-p)^{T-x} p^{x}}{\left(1-\frac{x}{T}\right)^{T-x}\left(\frac{x}{T}\right)^{x}}\right)
$$

where $p$ is the probability of failure in the $\alpha^{\text {th }}$ quantile? $L R$ asymptotic with a chi-square distribution $\left(\chi^{2}\right)$ with a degree of freedom is 1 . The null hypothesis is rejected if $L R$ greater than $\chi^{2}$. Accordingly, the VaR model is declared valid if the null hypothesis is accepted.

\section{Methodology}

The data in this paper is historical data obtained from https://finance.yahoo.com/ with MCAS code for PT. M Cash Integration Tbk stock and KIOS for PT. Kioson Commercial Indonesia stock. The data analyzed to gain insight into risk value from both companies by determined the $\mathrm{VaR}$ model. The VaR model was obtained by selected the best model MLAR. The VaR model is obtained by selecting the best MLAR model to obtain the estimated parameter value. The method of estimating parameters to obtain this value is the Bayesian method. Here are the steps for this analysis:

1. Calculate return from stock data (close) by assuming that income payments are zero with the following equation

$$
r_{t}=\frac{P_{t}+P_{t-1}}{P_{t-1}}
$$

where $r_{t}$ is the stock price return on the $t^{t h}$ day, $P_{t}$ is the stock price on the $t^{t h}$ day, and $P_{t-1}$ is the stock price on the $(t-1)^{t h}$ day (Jorion, 2011). This return is data will be analyzed in the next steps.

2. The understanding pattern of data by plotting using a marginal plot.

3. Determine the components that will be a mixture. These components are Autoregressive or $\operatorname{AR}(\mathrm{p})$ models. Step to determine these components:

a. Detecting stationarity of mean by creating a time series plot and ADF test. If data is not stationary, it must be different.

b. Detecting stationarity of variance by determining rounded value. If data is not filled that requirement, it must be transformed.

c. Create ACF and PACF plots to get order AR(p).

d. Estimate and hypothesis testing of parameter $\mathrm{AR}(\mathrm{p})$ using Bayesian normal methods.

4. Make $\operatorname{MLAR} \operatorname{MLAR}(K, p)$ order by mixture 2 components $\operatorname{AR}(\mathrm{p})$.

5. Estimate and hypothesis testing of parameter $\operatorname{MLAR}(K, p)$ using bayesian MLAR methods.

6. Calculate DIC for each MLAR model, then choose the model with the smallest DIC.

$$
D I C=\bar{D}+2 p_{D}
$$

$\bar{D}$ is the posterior mean of the deviance, which is defined as $-2 \log p(y \mid \theta) . p_{D}$ is 'the effective number of parameters', and is given by $p_{D}=\bar{D}-\widehat{D}$ where $\widehat{D}=-2 \log p(y \mid \bar{\theta})$ (Spiegelhalter, Best, Carlin, \& van der Linde, 2002). 
7. Determine VaR models with $5 \%$ and $1 \%$ quantiles.

8. Ensure VaR models are suitable.

9. Conclude.

These steps are applied for MCAS and KIOS.

\section{Results}

The identification of return characteristics is done by exploring the data that has been visualized by the marginal plot (see Figure 2). Figure 2 shows that the returns of the two stocks tend to be around zero so that the two data have a leptokurtic pattern (high peak). Outliers were also found in both returns, but the frequency of KIOS outliers was more and spread out than MCAS. This causes the return to be heavy tailed. Besides, the return conditions for the two stocks have a positive skewness (left-skewed), where the return conditions for MCAS are more sloping than KIOS. The identifications that have been carried out have described the return conditions for the two stocks that do not meet the normal distribution characteristics. Bayesian MLAR is used in this analysis to deal with the problem of returns that are not normally distributed. After ensuring that return data suit for analyzed using Bayesian MLAR, informative prior must be determined.

Informative prior determined by estimated autoregressive (AR) parameters. The first step is confirming that the return had the following assumption stationary in mean and variance. Stationery in the mean detected by time series plot and Augmented Dickey-Fuller (ADF) test to confirmed it. Figure 3 shows that the data have been stationary in the mean. This statement is also supported by the results of the ADF test where the null hypothesis is non-stationary data in the mean. With a significance level of 0.05 , the null hypothesis is rejected because the Pvalue is smaller than the significance level. The required stationary process in the mean have been filled, the next step is to detect a stationary process on the variance. Processes are detected with an integer value. In Table 2 the rounding values for both MCAS and KIOS are -1 which indicated the stationary process in variance unfulfilled. This means that a Box-cox transformation is necessary so that the stationary process for the variance is met. After the data are transformed, the data show that the stationary requirement in variance has been resolved. The requirement of the stationary process in mean and variance was filled, then the autoregressive order can be determined.

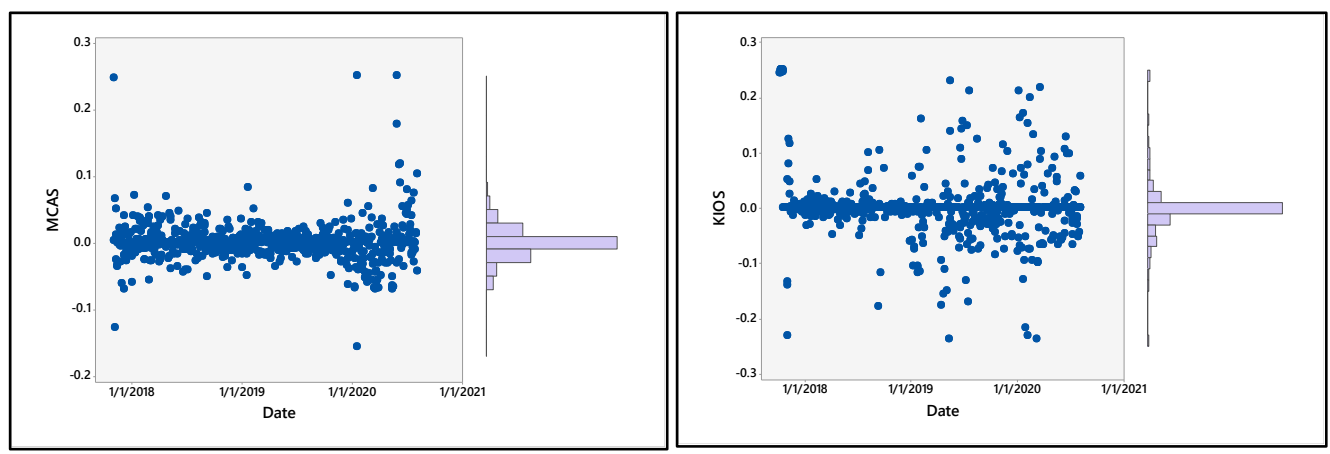

Figure 2: Marginal Plot of MCAS and KIOS Returns 


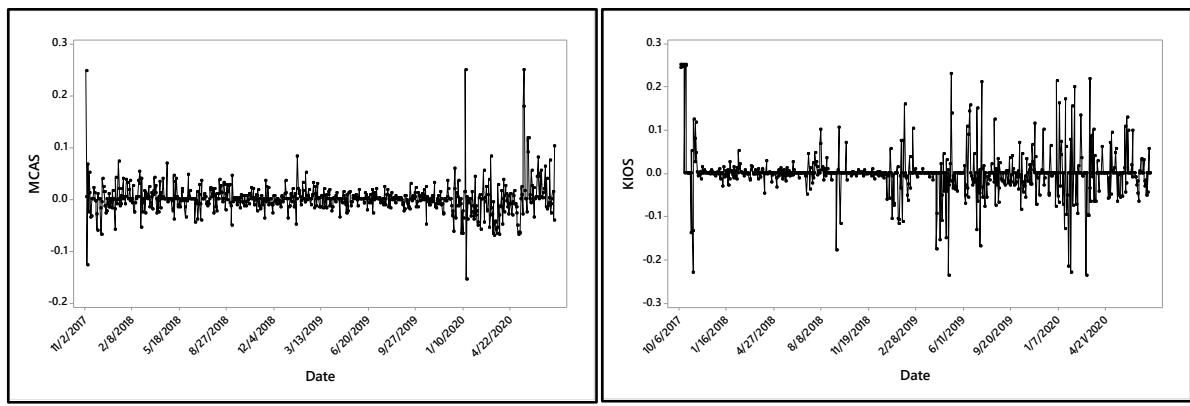

Figure 3: Time Series Plot of MCAS and KIOS Return

Table 1: ADF Test

\begin{tabular}{ccc}
\hline Stock & Estimation & P-value \\
\hline MCAS & -7.585 & 0.01 \\
\hline KIOS & -11.541 & 0.01 \\
\hline
\end{tabular}

Table 2: Box-Cox Transformation

\begin{tabular}{ccccc}
\hline $\begin{array}{c}\text { Box-Cox } \\
\text { Transformation }\end{array}$ & Stock & Lower CL & Upper CL & $\begin{array}{c}\text { Rounded } \\
\text { Value }\end{array}$ \\
\hline \multirow{2}{*}{ Before } & MCAS & -1.71 & -0.12 & -1 \\
\cline { 2 - 5 } & KIOS & 0.74 & 1.58 & 1 \\
\hline \multirow{2}{*}{ After } & MCAS & 0.43 & 1.49 & 1 \\
\cline { 2 - 5 } & KIOS & 0.74 & 1.58 & 1 \\
\hline
\end{tabular}

Determining the AR (p) order is the same as determining the ARIMA (p, d, q) order in general. However, in this case, only significant p-lag was detected in PACF (see Figure 4 for MCAS and Figure 5 for KIOS). The significant lag at the time of identification of the PACF must also be significant in the ACF (see Figure 4 for MCAS and Figure 5 for KIOS)). Significant lags on MCAS returns are 1, 5, and 7 while KIOS are 1, 2, and 3. The AR (p) model obtained from these lags is shown in Table 3 and Table 4.
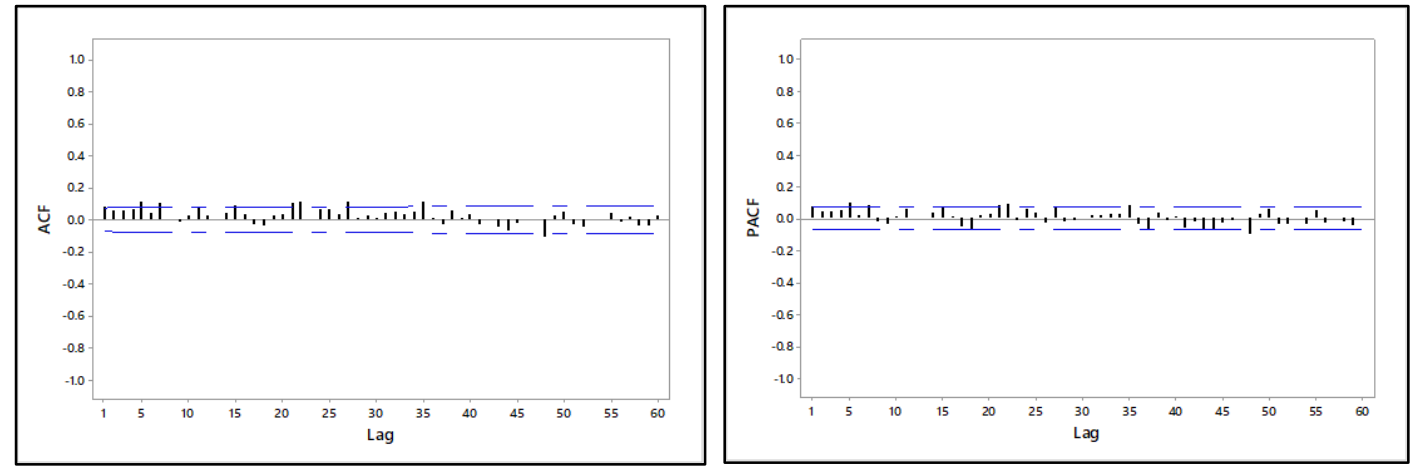

Figure 4: ACF and PACF of MCAS return 

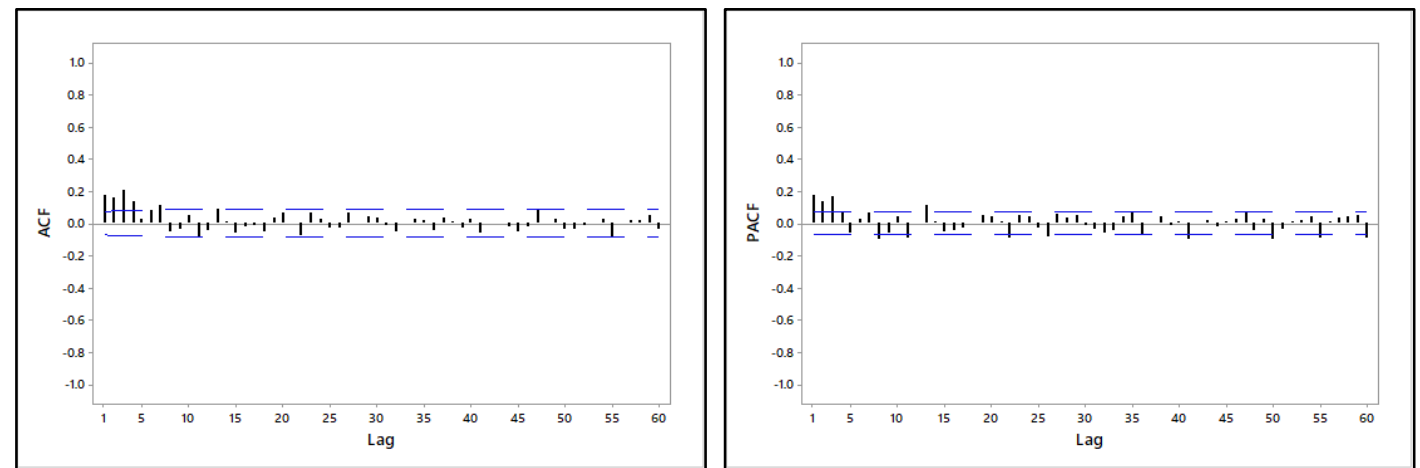

Figure 5: ACF and PACF of MCAS return

Informative prior is a significant parameter estimate value where the credible interval does not contain zero. Table 3 presents the parameter estimates of all models from the MCAS return data that has been determined to be significant, as well as for the KIOS return data (see Table 4). Since the objective of parameter estimation is only to determine prior parameter values for MLAR, a diagnostic check for the residuals was not performed.

Table 3: Parameters Estimated MCAS Autoregressive Model

\begin{tabular}{|c|c|c|c|c|c|}
\hline Model & Parameter & Estimation & $\begin{array}{c}\text { Standard } \\
\text { Deviation }\end{array}$ & $2.50 \%$ & $97.50 \%$ \\
\hline \multirow{2}{*}{$\mathrm{AR}([1])$} & $\phi_{1}$ & 0.100 & 0.036 & 0.031 & 0.172 \\
\hline & $\sigma$ & 0.029 & 0.001 & 0.027 & 0.030 \\
\hline \multirow{2}{*}{$\mathrm{AR}([5])$} & $\phi_{5}$ & 0.100 & 0.035 & 0.031 & 0.170 \\
\hline & $\sigma$ & 0.028 & 0.001 & 0.027 & 0.030 \\
\hline \multirow{2}{*}{$\operatorname{AR}([7])$} & $\phi_{7}$ & 0.093 & 0.035 & 0.024 & 0.163 \\
\hline & $\sigma$ & 0.028 & 0.001 & 0.027 & 0.030 \\
\hline \multirow{3}{*}{$\operatorname{AR}([1,5])$} & $\phi_{1}$ & 0.129 & 0.038 & 0.056 & 0.203 \\
\hline & $\phi_{5}$ & 0.095 & 0.040 & 0.026 & 0.165 \\
\hline & $\sigma$ & 0.028 & 0.001 & 0.026 & 0.029 \\
\hline \multirow{3}{*}{$\operatorname{AR}([1,7])$} & $\phi_{1}$ & 0.130 & 0.038 & 0.057 & 0.205 \\
\hline & $\phi_{7}$ & 0.087 & 0.040 & 0.017 & 0.156 \\
\hline & $\sigma$ & 0.001 & 0.000 & 0.001 & 0.001 \\
\hline \multirow{3}{*}{$\operatorname{AR}([5,7])$} & $\phi_{5}$ & 0.085 & 0.037 & 0.013 & 0.158 \\
\hline & $\phi_{7}$ & 0.090 & 0.040 & 0.020 & 0.160 \\
\hline & $\sigma$ & 0.028 & 0.001 & 0.027 & 0.030 \\
\hline \multirow{4}{*}{$\operatorname{AR}([1,5,7])$} & $\phi_{1}$ & 0.127 & 0.038 & 0.053 & 0.201 \\
\hline & $\phi_{5}$ & 0.079 & 0.043 & 0.005 & 0.152 \\
\hline & $\phi_{7}$ & 0.084 & 0.037 & 0.015 & 0.154 \\
\hline & $\sigma$ & 0.028 & 0.001 & 0.026 & 0.029 \\
\hline
\end{tabular}


Volume 2 Issue 5 (December 2020) PP. 21-33 DOI 10.35631/AIJBAF.25002

Table 4: Parameters Estimated KIOS Autoregressive Model

\begin{tabular}{|c|c|c|c|c|c|}
\hline Model & Parameter & Estimation & $\begin{array}{l}\text { Standard } \\
\text { Deviation }\end{array}$ & $2.50 \%$ & $\mathbf{9 7 . 5 0 \%}$ \\
\hline \multirow{2}{*}{$\operatorname{AR}([1])$} & $\phi_{1}$ & 0.175 & 0.036 & 0.106 & 0.247 \\
\hline & $\sigma$ & 0.053 & 0.001 & 0.051 & 0.056 \\
\hline \multirow{2}{*}{$\mathrm{AR}([2])$} & $\phi_{2}$ & 0.163 & 0.036 & 0.095 & 0.234 \\
\hline & $\sigma$ & 0.053 & 0.001 & 0.050 & 0.055 \\
\hline \multirow{2}{*}{$\mathrm{AR}([3])$} & $\phi_{3}$ & 0.209 & 0.035 & 0.142 & 0.278 \\
\hline & $\sigma$ & 0.051 & 0.001 & 0.049 & 0.054 \\
\hline \multirow{3}{*}{$\operatorname{AR}([1,2])$} & $\phi_{1}$ & 0.125 & 0.037 & 0.055 & 0.197 \\
\hline & $\phi_{2}$ & 0.141 & 0.038 & 0.070 & 0.212 \\
\hline & $\sigma$ & 0.052 & 0.001 & 0.050 & 0.055 \\
\hline \multirow{3}{*}{$\operatorname{AR}([1,3])$} & $\phi_{1}$ & 0.091 & 0.036 & 0.021 & 0.163 \\
\hline & $\phi_{3}$ & 0.194 & 0.037 & 0.125 & 0.263 \\
\hline & $\sigma$ & 0.051 & 0.001 & 0.049 & 0.054 \\
\hline \multirow{3}{*}{$\operatorname{AR}([2,3])$} & $\phi_{2}$ & 0.104 & 0.036 & 0.035 & 0.175 \\
\hline & $\phi_{3}$ & 0.191 & 0.037 & 0.122 & 0.260 \\
\hline & $\sigma$ & 0.051 & 0.001 & 0.048 & 0.054 \\
\hline \multirow{4}{*}{$\operatorname{AR}([1,2,3])$} & $\phi_{1}$ & 0.080 & 0.036 & 0.009 & 0.150 \\
\hline & $\phi_{2}$ & 0.094 & 0.036 & 0.024 & 0.165 \\
\hline & $\phi_{3}$ & 0.179 & 0.037 & 0.109 & 0.249 \\
\hline & $\sigma$ & 0.051 & 0.001 & 0.048 & 0.054 \\
\hline
\end{tabular}

Bayesian MLAR in this paper is limited to $2(\mathrm{~K}=2)$ mixture components. The combined components are the predetermined AR (p). The amount of mixture formed for each return was 42 mixture. The combination is then analyzed with Bayesian MLAR to obtain estimates on the parameters formed. Similar to AR (p), the selected model is a significant MLAR model or the 95\% credible interval does not contain zero. Furthermore, the best models that meet the requirements of significance are selected based on DIC. In this paper, the parameter estimation results include only the best models based on the DIC for each return (see Tables 5 and 6).

Table 5: Parameters Estimated MCAS Autoregressive MLAR(2;[1],[5]) Model

\begin{tabular}{crrrr}
\hline Parameter & Mean & $\begin{array}{r}\text { Standard } \\
\text { Deviation }\end{array}$ & $\mathbf{2 . 5 0 \%}$ & $\mathbf{9 7 . 5 0 \%}$ \\
\hline$\pi_{1}$ & 0.501 & 0.013 & 0.475 & 0.528 \\
\hline$\pi_{2}$ & 0.499 & 0.013 & 0.472 & 0.525 \\
\hline$\phi_{1,1}$ & 0.100 & 0.002 & 0.096 & 0.104 \\
\hline$\phi_{2,5}$ & 0.099 & 0.002 & 0.095 & 0.103 \\
\hline$\sigma_{1}$ & 0.023 & 0.001 & 0.022 & 0.025 \\
\hline$\sigma_{2}$ & 0.023 & 0.001 & 0.021 & 0.025 \\
\hline
\end{tabular}


Table 6: Parameters Estimated KIOS Autoregressive MLAR(2;[2],[3]) Model

\begin{tabular}{crrrr}
\hline Parameter & Mean & $\begin{array}{r}\text { Standard } \\
\text { Deviation }\end{array}$ & $\mathbf{2 . 5 0 \%}$ & $\mathbf{9 7 . 5 0 \%}$ \\
\hline$\pi_{1}$ & 0.500 & 0.013 & 0.475 & 0.526 \\
\hline$\pi_{2}$ & 0.500 & 0.013 & 0.474 & 0.526 \\
\hline$\phi_{1,2}$ & 0.162 & 0.002 & 0.158 & 0.166 \\
\hline$\phi_{2,3}$ & 0.208 & 0.002 & 0.203 & 0.212 \\
\hline$\sigma_{1}$ & 0.037 & 0.001 & 0.035 & 0.040 \\
\hline$\sigma_{2}$ & 0.038 & 0.001 & 0.035 & 0.040 \\
\hline
\end{tabular}

Table 7: Value at Risk

\begin{tabular}{llrr}
\hline \multirow{2}{*}{ Stock } & \multirow{2}{*}{$\begin{array}{c}c \\
\text { Investment }\end{array}$} & \multicolumn{2}{c}{ VaR } \\
\cline { 3 - 4 } & $\mathbf{5 \%}$-Quantile & $\mathbf{1 \%}$-Quantile \\
\hline MCAS & 1-day & -0.0384 & -0.0747 \\
\hline & 5-days & -0.0859 & -0.1669 \\
\hline KIOS & 20-days & -0.1717 & -0.3339 \\
\hline & 1-day & -0.0622 & -0.121 \\
\hline & 5-days & -0.1391 & -0.2705 \\
\hline & 20-days & -0.2783 & -0.5411 \\
\hline
\end{tabular}

The parameter estimation results from the best model that have been obtained from the previous stages are used to calculate VaR. The results of the VaR calculation (see Table 6) explain that the longer the investors invest their shares and the smaller the quantile used, the greater the risk to be faced. The risk faced by investors when investing in KIOS will be greater than that of MCAS. This is in line with the condition of the KIOS stock which tends to decline over time (Figure 6). The VaR calculation results for KIOS shares show that in the 5\%-quantile with an investment of one day it produces a VaR of 0.0622 , which means that an investor investing $\$$ 36.00 has a $5 \%$ chance of losing more than $\$ 1.80$ of this investment over the next one day or the maximum risk of loss for the investor is $\$ 1.80$.

The results of VaR calculations need to be tested to find out whether it is valid or not. Therefore, backtesting was carried out using the Kupiec POF test. The null hypothesis is $p=\hat{p}$ and the alternative hypothesis is $p \neq \hat{p}$. Table 8 shows that at a significance level of 0.05 the decision that can be taken is to accept the null hypothesis at the 5\%-quantile, while the $1 \%$-quantile is rejected. The decision means that all models at the 5\%-quantile that are formed are accurate, but not yet accurate for the $1 \%$-quantile. 

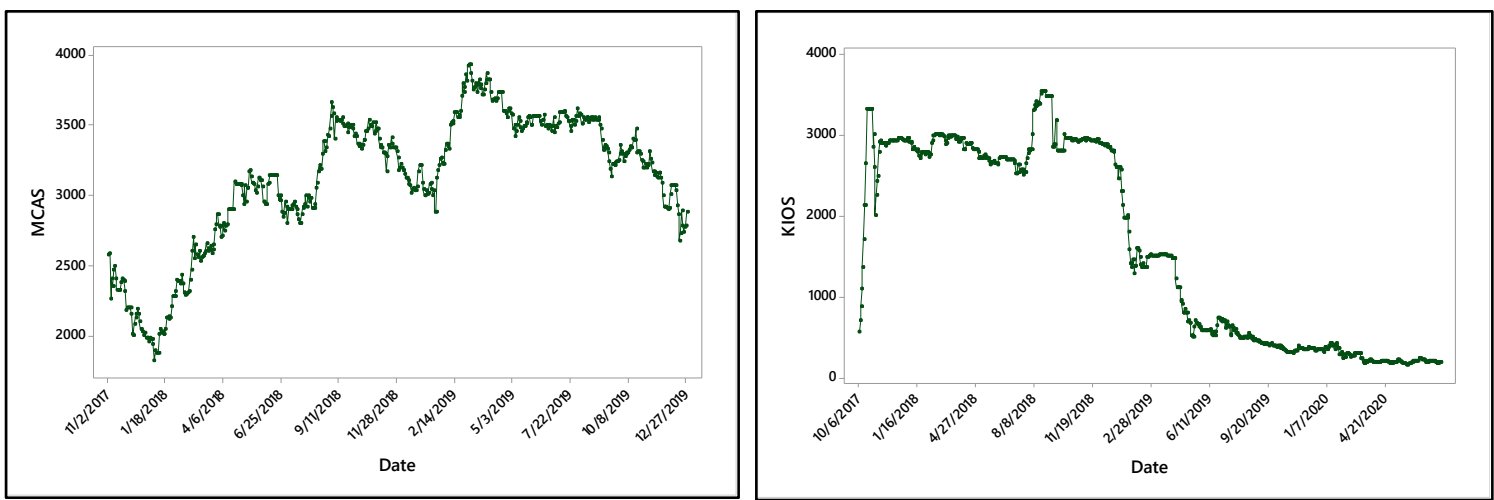

Figure 6: MCAS and KIOS Stock Plots (Close)

Table 8: ADF Kupiec POF Test Result

\begin{tabular}{ccccl}
\hline Stock & 1-day VaR & LR & $\boldsymbol{\chi}^{\mathbf{2}}$ & Decision \\
\hline \multirow{2}{*}{ MCAS } & 5\%-Quantile & 0.21 & 3.84 & Accept \\
\cline { 2 - 5 } & 1\%-Quantile & 5.11 & 3.84 & Reject \\
\hline \multirow{2}{*}{ KIOS } & 5\%-Quantile & 3.62 & 3.84 & Accept \\
\cline { 2 - 5 } & 1\%-Quantile & 4.97 & 3.84 & Reject \\
\hline
\end{tabular}

\section{Conclusion}

Based on the analysis results, it can be concluded that the VaR model can be obtained by using the Bayesian MLAR model approach (2; [1], [5]) for MCAS stocks and the MLAR model (2; [2], [3]) for KIOS stocks. From the results of VaR modeling using the results of the MLAR model approach, the VaR model is obtained at 5\% and 1\% quantiles. To ensure that the model is accurate or not, backtesting is carried out using the Kupiec POF test approach. The test results show that the only accurate model is the VaR model at the 5\%-quantile. The VaR model for MCAS and KIOS shares in the 5\%-quantile represents the risks that investors might face if investing in KIOS shares is greater than MCAS. The VaR calculation results for KIOS shares show that in the 5\%-quantile with an investment of one day it produces a VaR of 0.0622 , which means that an investor investing \$ 36.00 has a 5\% chance of losing more than $\$ 1.80$ of this investment over the next one day or the maximum risk of loss for the investor is $\$ 1.80$.

\section{References}

Abad, P., Benito, S., \& López, C. (2013). A comprehensive review of Value at Risk methodologies. The Spanish Review of Financial Economics, 12(1), 15-32. doi:https://doi.org/10.1016/j.srfe.2013.06.001

Butler, C. (1999). Mastering Value at Risk. New York: Pretice Hall.

Dowd, K. (2006). Retrospective Assessment of Value-at-Risk. Risk Management: A Modern Perspective, 183-202.

Iorgulescu, F. (2012). Backtesting value-at-risk: Case study on the Romanian capital market. Procedia - Social and Behavioral Sciences, 62, $796-800$. doi:https://doi.org/10.1016/j.sbspro.2012.09.134

Jorion, P. (2011). Value at Risk The New Benchmark for Managing Financial Risk (3 ed.). New York: McGraw-Hill.

Kansantaloustiede, Tutkielma, M. T., \& Nieppola, O. (2009). Backtesting Value-at-Risk Models. Helsinki: Helsinki School Of Economics. 
Kotz, S., Kozubowski, T. J., \& Podgorski, K. (2001). The Laplace Distribution and Generalizations: A Revisit with Applications to Communications, Economics, Engineering, and Finance. New York: Springer Science+Business Media, LLC.

Kupiec, P. H. (1995). Techniques for verifying the accuracy of risk measurement models. The Journal of Derivatives, 3, 73-84.

Laucereno, S. F. (2019, Agustus 7). Fintech. Retrieved from Detik Finance: https://finance.detik.com/fintech/d-4656166/saham-unicorn-ri-dikuasai-asing-apadampaknya

Miftahurrohmah, B., Iriawan, N., \& Fithriasari, K. (2017). On The Value at Risk Using Bayesian Mixture Laplace Autoregressive Approach for Modelling the Islamic Stock Risk Investment. Journal of Physics: Conference Series, 855(1), 1.

Nguyen, H. D., \& McLachlan, G. J. (2016). Laplace mixture of linear experts. Computational Statistics and Data Analysis 93, 177-191.

Nguyen, H. D., Geoffrey, M. J., Ullmann, J. F., \& Janke, A. L. (2016). Laplace mixture autoregressive models. Statistics and Probability Letters 110, 18-24.

Putri, U. M. (2016). Analisis Risiko Investasi Saham Syariah Menggunakan Metode Value at Risk dengan Pendekatan Mixture Normal Autoregressive. Surabaya: Institut Teknologi Sepuluh Nopember.

Sidik, S. (2019, Januari 10). Market. Retrieved from CNBC Indonesia: https://www.cnbcindonesia.com/market/20190110182805-17-50105/ini-alasanunicorn-indonesia-enggan-melantai-di-bei

Spiegelhalter, D. J., Best, N. G., Carlin, B. P., \& van der Linde, A. (2002). Bayesian Measures of Model Complexity and Fit" (with discussion). Journal of the Royal Statistical Society, 64, 583-639.

Summinga-Sonagadu, R., \& Narsoo, J. (2019). Risk Model Validation: An Intraday VaR and ES Approach Using the Multiplicative. Risk, 7(10), 1-23. doi:https://doi.org/10.3390/risks7010010 